\title{
Efficacy and Safety of Olanzapine/Fluoxetine Combination vs Fluoxetine Monotherapy Following Successful Combination Therapy of Treatment-Resistant Major Depressive Disorder
}

\author{
Elizabeth Brunner*,', Mauricio Tohen ${ }^{2}$, Olawale Osuntokun', John Landry ${ }^{3}$ and Michael E Thase ${ }^{4}$ \\ 'Eli Lilly and Company, Indianapolis, IN, USA; 'Department of Psychiatry, Health Sciences Center, University of New Mexico, Albuquerque, NM, \\ USA; ${ }^{3}$ Eli Lilly Canada, Toronto, ON, USA; ${ }^{4}$ Perelman School of Medicine of the University of Pennsylvania, Philadelphia Veterans Affairs Medical \\ Center and the University of Pittsburgh Medical Center, Pittsburgh, PA, USA
}

\begin{abstract}
This study assessed prevention of relapse in patients with treatment-resistant depression (TRD) taking olanzapine/fluoxetine combination (OFC). Patients with major depressive disorder (MDD) who failed to satisfactorily respond to $\geqslant 2$ different antidepressants for $\geqslant 6$ weeks within the current MDD episode were acutely treated for 6-8 weeks, followed by stabilization ( 12 weeks) on OFC. Those who remained stable were randomized to OFC or fluoxetine for up to 27 weeks. Time-to-relapse was the primary efficacy outcome defined as 50\% increase in Montgomery-Åsberg Depression Rating Scale score with Clinical Global Impressions - Severity of Depression score of $\geqslant 4$; hospitalization for depression or suicidality; or discontinuation for lack of efficacy or worsening of depression or suicidality. A total of 444 patients were randomized I:I to OFC $(N=22$ I) or fluoxetine $(N=223)$. Time-to-relapse was significantly longer in OFC-treated patients compared with fluoxetine-treated patients $(p<0.00 \mathrm{I})$. Treatment-emergent weight gain and some mean and categorical fasting metabolic changes were significantly greater in OFC-treated patients. Clinically significant weight gain ( $\geqslant 7 \%$ ) was observed in $55.7 \%$ of patients who remained on OFC throughout the study, including the relapse-prevention phase (up to 47 weeks). There were no significant differences between patients treated with OFC and fluoxetine in extrapyramidal symptoms or serious adverse events. We believe this is the first controlled relapse-prevention study in subjects with TRD that supports continued use of a second-generation antipsychotic beyond stabilization. A thorough assessment of benefits and risks (in particular metabolic changes) associated with continuing treatment with OFC or fluoxetine must be done based on individual patient needs.

Neuropsychopharmacology (20I4) 39, 2549-2559; doi:I0.I038/npp.20I4.I0I; published online 28 May 20I4
\end{abstract}

\section{INTRODUCTION}

Treatment-resistant depression (TRD) is a chronic debilitating condition with profound sequelae. Only one-third of patients remit after receiving first-line therapy for major depressive disorder (MDD (Trivedi et al, 2006), and approximately half of patients who do not respond to the first antidepressant therapy will not respond to a second agent (US Department of Health and Human Services, Public Health Services, Agency for Healthcare Research and Quality, 1993). Even after multiple interventions, approximately onequarter of patients remain depressed, and the likelihood of response to antidepressants decreases with the number of failed treatment courses (Rush et al, 2006). Furthermore, those who require multiple antidepressant interventions appear to be at significantly greater risk of subsequent relapse despite ongoing therapy (Rush et al, 2006).

* Correspondence: Dr E Brunner, Global Product Safety, Eli Lilly and Company, Lilly Corporate Center, Indianapolis, IN 46285, USA, Tel: + 317276 5366, Fax: + 317276 6445,

E-mail: brunner_elizabeth@lilly.com

Received I8 December 2013; revised I4 March 2014; accepted 31

March 2014; accepted article preview online 7 May 2014
Increased morbidities, such as increased risk of substance abuse, greater social, and vocational impairment, higher suicide risk, and greater resource utilization, are all associated with TRD (Papakostas et al, 2003). In contrast to depressed persons without TRD, patients with TRD are at least twice as likely to be hospitalized, are prescribed up to three times as many psychotropic medications, and have higher medical costs owing to polypharmacy (Crown et al, 2002; Greden, 2001).

Relapse in depression comes at high medical, social, and economic costs (Trivedi, 2004; Wade and Häring, 2010); and most clinicians strive to prevent patients with MDD from relapsing. Relapse rates in difficult-to-treat patients may be higher than a non-treatment-resistant population; $\mathrm{STAR}^{*} \mathrm{D}$ analyses found that $\sim 25 \%$ of treatment-resistant patients who remitted on level 1 citalopram relapsed within 6-12 months of achieving remission (Ishak et al, 2013). The STAR ${ }^{\star} \mathrm{D}$ trial also found that those who required more treatment levels to achieve remission had higher relapse rates, potentially reflecting that the more difficult-to-treat populations are at an even greater risk of relapse (Gaynes et al, 2008).

Numerous treatment strategies have been employed to manage TRD, including augmentation with lithium (Berwaerts 
et al, 2011) or second-generation antipsychotics (SGAs) (De Bartolomeis and Perugi, 2012; Kemp et al, 2012; Rapaport et al, 2006; Weisler et al, 2011), switching antidepressants (Baldomero et al, 2005; Rush et al, 2006), and combining antidepressants (Blier et al, 2009, 2010; Carpenter et al, 2002; Maes et al, 1999; Nelson et al, 2004). Cumulative evidence supports SGA augmentation in most guidelines for partial or nonresponders in clinical practice (American Psychiatric Association, 2010; Anderson et al, 2008; Bauer et al, 2002; Kennedy et al, 2009).

Olanzapine/fluoxetine combination (OFC) is a combination of the antipsychotic, olanzapine, and the antidepressant, fluoxetine. The short-term effectiveness of OFC for TRD is supported by results from randomized, controlled, and acute-phase studies (Corya et al, 2006; Shelton et al, 2001, 2005; Thase et al, 2007; Trivedi et al, 2009). In each study, OFC rapidly reduced depressive symptoms, with three of the studies showing significantly greater improvement than antidepressant monotherapy at study endpoint (Corya et al, 2006; Shelton et al, 2001; Thase et al, 2007). Additionally, in a 76-week, open-label study, OFC showed rapid and sustained improvement of depressive symptoms in patients with MDD, including patients with TRD (Corya et al, 2003).

The effectiveness of OFC in this patient population beyond 8 weeks has not been established in controlled clinical studies. Because it is generally accepted that TRD is a chronic illness requiring chronic treatment, physicians should periodically reexamine the need for continued OFC treatment. However, the question of how long a patient should be treated or maintained with OFC benefit remains. For instance, once the patient achieves a level of clinical stabilization on OFC, can the antipsychotic then be removed? The following study compared time-to-relapse in patients stabilized on OFC who were then randomized to either continued OFC treatment or treatment with fluoxetine alone across a 27-week period of double-blind treatment.

\section{MATERIALS AND METHODS}

\section{Patient Population}

Eligible patients were men and women, inpatients or outpatients, aged 18-65 years diagnosed with single or recurrent unipolar MDD without psychotic features, defined by the Diagnostic and Statistical Manual of Mental Disorders, Fourth Edition, Text Revision (DSM-IV-TR) (American Psychiatric Association, 2000) and confirmed by the Structured Clinical Interview for DSM (SCID)-I Clinical Version, including MDD specifiers in the Research Version of SCID-1 (diagnoses 296.31, 296.32, and 296). Patients were required to have a 17 -item Hamilton Depression Scale score $\geqslant 18$ at visits 1 and 2 . TRD, defined as failure to achieve a satisfactory antidepressant response to adequate and separate treatment courses ( $\geqslant 6$ weeks for each medication) of $\geqslant 2$ different antidepressants in the current MDD episode. Permitted antidepressant failures/treatments with equivalent doses considered appropriate for protocol subjects were provided. Patients previously resistant or nonresponsive to fluoxetine or OFC were excluded to ensure that patients who were known as nonresponders did not influence study results.
Patients with the following disorders or treatments were excluded: schizophrenia and related disorders, Bipolar Disorder I or II; diagnosis of substance dependence according to DSM-IV-TR criteria $\leqslant 30$ days before visit 1 ; Parkinson's disease or related disorders, postpartum depression, MDD with atypical features or with a seasonal pattern, or certain personality disorders (schizoid, schizotypal, antisocial, and borderline); psychotic symptoms 1 month before entering the study or current; current suicidal ideation per investigator's opinion; treatment with electroconvulsive therapy or vagus nerve stimulation within the current episode; treatment with clozapine or a monoamine oxidase inhibitor $\leqslant 14$ days before visit 1; or with remoxipride within 6 months prior to visit 2 .

\section{Study Design}

This was a multicenter, randomized, double-blind, activecomparator-controlled, parallel-group, phase 3 study conducted between July 2009 and March 2012 at multiple centers in Argentina, India, Mexico, Puerto Rico, Russia, South Africa, Turkey, and the United States. The study consisted of four study periods (Figure 1a). Patients entered a 3 - to 14-day screening period (Study Period I (SPI)). Eligible patients continued to a 6- to 8-week, open-label, acute treatment period and were assessed weekly (Study Period II (SPII)). Patients who met the response criteria, defined as $\geqslant 50 \%$ improvement from baseline on the MontgomeryÀsberg Depression Rating Scale (MADRS) (Montgomery and Asberg, 1979) and a Clinical Global Impressions-Severity of Depression (CGI-S) (Psychopharmacology Research Branch, National Institute of Mental Health, 1976b) score $\leqslant 3$, after $\geqslant 6$ weeks of treatment, were permitted to move into a 12-week open-label stabilization period (Study Period III (SPIII)); patients were discontinued from SPII if response criteria were not met by 8 weeks. During the 12 -week stabilization period (SPIII), patients were assessed weekly and had to maintain $\geqslant 50 \%$ improvement relative to baseline (visit 2) on MADRS and maintain CGI-S scores $\leqslant 3$ at all stabilization phase visits to be eligible for randomization to the double-blind, relapse-prevention period (Study Period IV (SPIV)); up to three excursions from these criteria were allowed, provided the excursions did not occur at consecutive visits nor at the last visit of the stabilization phase. Eligible stabilized patients were then randomly assigned in a $1: 1$ ratio to either receive fluoxetine only or continue receiving OFC during a 27-week, double-blind, relapse-prevention period (SPIV) in which they were assessed a total of nine times at weeks $21,23,25,29,33,37,41,45$, and 47 of the study. To minimize bias, investigators and patients were blinded to stabilization criteria during SPIII, timing of the start of the relapse-prevention phase with either OFC or fluoxetine, and criteria for continuation in SPIV.

During SPII and SPIII, to increase tolerability, patients were initiated at a $3 / 25$ dose (SPII only) and then flexibly dosed thereafter using doses of $6 / 25,12 / 25,6 / 50,12 / 50$, and $18 / 50 \mathrm{mg} /$ day (olanzapine/fluoxetine). A forced titration scheme was implemented whereby patients who had not met criteria for improvement, did not have potentially doserelated adverse events (AEs), and had not achieved the maximum dose of medication had their dosage increased.

During SPIV, all patients followed a fixed dosing regimen. Patients randomized to OFC continued the same dose 
a

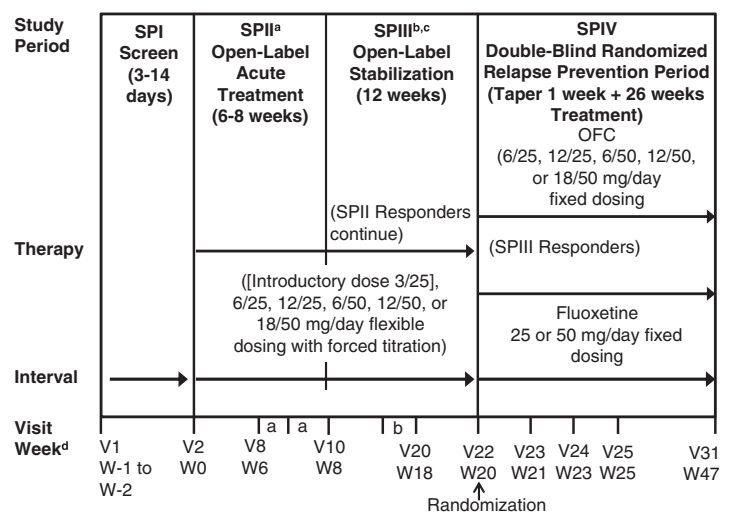

b

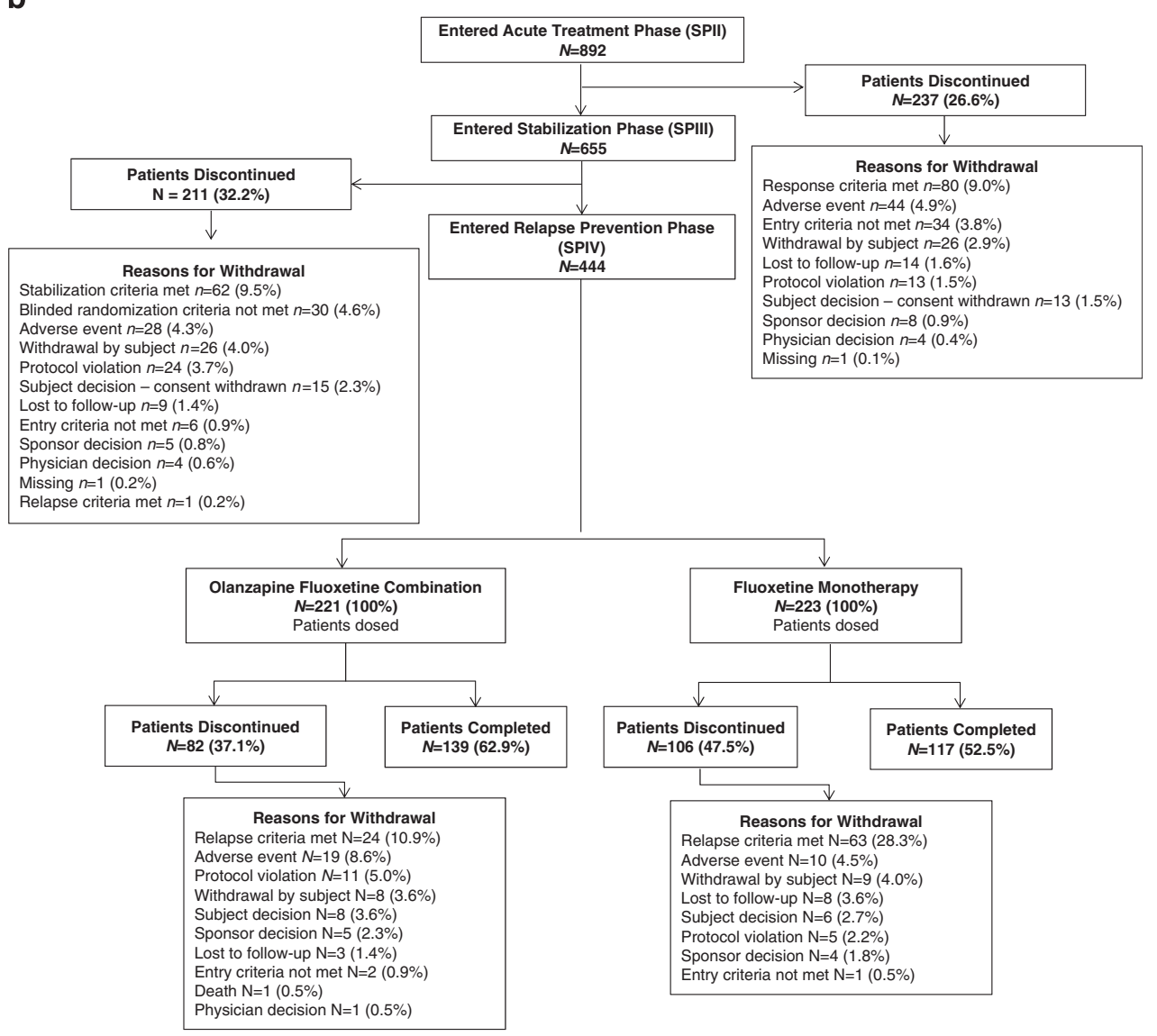

Figure I (a) Study design. N/n, number of patients; OFC, olanzapine and fluoxetine hydrochloride combination; SP, study period; $V$, visit; W, week. (b) Patient disposition. ${ }^{a}$ Patients moved into the stabilization study period after at least 6 weeks of treatment (at visits 8 or 9 ) if they met response criteria. The patient's next visit after the move was in SPIII at visit II. Patients who did not meet response criteria by visit 10 were discontinued from the study. bDose changes were not allowed after visit 19. 'Patients who did not meet stabilization criteria were discontinued from the study. ${ }^{\mathrm{d}}$ The week number designations used in this figure represent the maximum number of weeks according to the overall trial design, and not the duration of treatment for each patient.

received at the end of the open-label stabilization period. Patients randomized to fluoxetine maintained a fixed dose of fluoxetine consistent with their last OFC dose (25 or $50 \mathrm{mg}$ ). During the first week of SPIV, the fluoxetine-treated patients also continued to receive a gradually tapered concomitant dose of olanzapine to minimize inadvertent unblinding secondary to abrupt removal of a sedating agent. All patients in SPIV received the same number of capsules.

\section{Study Measures}

The primary efficacy assessment was to evaluate the longterm efficacy of OFC $v s$ fluoxetine in the treatment of 
patients with TRD, as measured by the time-to-relapse during the double-blind period. Relapse was defined as meeting any of the following criteria: $50 \%$ increase in the MADRS score from randomization with concomitant CGI-S score increase to $\geqslant 4$; hospitalization for depression or suicidality; or discontinuation due to lack of efficacy or worsening of depression or suicidality. Secondary efficacy measures included assessment of rates of relapse and timeto-relapse for each of the three individual relapse criteria. Response, stabilization, and remission rates were also assessed. Response was defined as $\geqslant 50 \%$ improvement from baseline on MADRS and a CGI-S score $\leqslant 3$, and remission was defined as a MADRS score $\leqslant 8$. Additional secondary assessments included the Sheehan Disability Scale (Sheehan et al, 1996) and collection of resource utilization and hospitalization data.

Safety assessments included reports of spontaneous AEs collected at every visit, vital signs, laboratory analytes, and electrocardiograms. Suicide-related thoughts and behaviors were assessed using the Columbia Suicide Severity Rating Scale (C-SSRS) (Posner et al, 2011), and emergence of mania was measured by incidence of treatment-emergent adverse events (TEAEs) possibly related to mania. Extrapyramidal symptoms (EPS) were assessed using the Barnes Akathisia Scale (BAS) (Barnes, 1989), Simpson-Angus Scale (Simpson and Angus, 1970), and the Abnormal Involuntary Movement Scale (AIMS) (Psychopharmacology Research Branch, National Institute of Mental Health, 1976a).

\section{Statistical Analyses}

Time-to-relapse was analyzed using the Kaplan-Meier survival estimation method, and log-rank test was used for treatment group comparison. For a more complete assessment of the magnitude of treatment effect on time-torelapse, a post hoc Cox proportional hazards model was also applied to obtain a related hazard ratio. Differences in rates of relapse, response, and remission were tested using Cochran-Mantel-Haenszel tests adjusting for country. Paired $t$-tests or Wilcoxon tests were used for continuous variables within treatment groups. A mixed model for repeated measures was used for comparisons between treatment groups for continuous variables. Tests of safety measures between treatment groups were performed using Fisher's exact test. All tests were two-sided using a significance level of 0.05 with no adjustments for multiplicity. The test addressing the primary objective was confirmatory, whereas all others were suggestive.

\section{RESULTS}

Patient disposition is summarized in Figure 1b.

\section{Acute and Stabilization Phases (SPII and SPIII)}

Of 892 patients who entered SPII, 237 (26.6\%) discontinued; the most common reason for early discontinuation was 'response criteria not met' $(N=80(9.0 \%))$. Of 655 patients who entered SPIII, $211(32.2 \%)$ discontinued, with the most common reason for early discontinuation being 'stabilization criteria not met' $(N=62(9.5 \%)$; Figure $1 \mathrm{~b})$. Patient demographics and characteristics were similar between SPII and SPIII (Table 1A).

Efficacy. The mean MADRS total score of all patients entering SPII was 30.4 and the mean CGI-S score was 4.6. Patients at SPIII entry had a mean MADRS total score of 9.3 and a mean CGI-S score of 2.3 (Table 1A).

Safety. There were no deaths during SPII and SPIII; 13 $(1.5 \%)$ and $9(1.4 \%)$ patients, respectively, reported $\geqslant 1$ serious adverse event (SAE), whereas 44 (4.9\%) and 28 (4.3\%), respectively, discontinued owing to an AE. A total of $610(68.4 \%)$ and $352(53.7 \%)$ patients reported TEAEs during SPII and SPIII, respectively (Table 2). Nineteen $(2.3 \%)$ and seven $(1.1 \%)$ patients, respectively, reported treatment-emergent akathisia as defined by the BAS (global score $<2$ at baseline and global score $\geqslant 2$ post baseline). Fourteen $(1.7 \%)$ and $20(3.1 \%)$ patients, respectively, reported treatment-emergent Parkinsonism as defined by the SAS (total score $\leqslant 3$ of items $1-10$ at baseline and a total score $>3$ of items 1-10 post baseline). No patients in SPII reported treatment-emergent dyskinesia as defined with AIMS (score $\geqslant 3$ on any one item post baseline or scores $\geqslant 2$ on any two items post baseline among patients without either criterion at baseline), whereas five (0.8\%) patients

Table IA Baseline Patient Demographics and Clinical Characteristics of Patients (Study Periods II and III)

\begin{tabular}{|c|c|c|}
\hline Characteristic & $\begin{array}{l}\text { SPII OFC, } \\
N=892\end{array}$ & $\begin{array}{l}\text { SPIII OFC, } \\
\quad N=655\end{array}$ \\
\hline Age (years), mean (SD) & $44.4(12.0)$ & $44.4(12.0)$ \\
\hline \multicolumn{3}{|l|}{ Gender, n (\%) } \\
\hline Male & $301(33.7)$ & $212(32.4)$ \\
\hline Female & $591(66.3)$ & $443(67.6)$ \\
\hline \multicolumn{3}{|l|}{ Race, $n$ (\%) } \\
\hline Caucasian & $634(71.1)$ & $470(71.8)$ \\
\hline Other & $255(28.9)$ & $183(28.2)$ \\
\hline Body weight (kg), mean (SD) & $80.4(21.6)$ & $82.5(22.0)$ \\
\hline Height (cm), mean (SD) & $166.0(9.6)$ & $165.4(9.4)$ \\
\hline $\mathrm{BMI}\left(\mathrm{kg} / \mathrm{m}^{2}\right)$, mean $(\mathrm{SD})$ & $29.1(7.4)$ & $30.1(7.3)$ \\
\hline Age at first episode (years), mean (SD) & $30.8(12.8)$ & $31.0(12.9)$ \\
\hline Age at current episode (years), mean (SD) & $42.2(12.2)$ & $42.4(12.3)$ \\
\hline Number of previous episodes ${ }^{\mathrm{a}}$, mean (SD) & $4.3(9.8)$ & $3.9(7.5)$ \\
\hline $\begin{array}{l}\text { Duration of current episode (days), } \\
\text { mean (SD) }\end{array}$ & $651.1(\mid 155.6)$ & $640.6(1167.0)$ \\
\hline MADRS total score (SD) & $30.4(5.3)$ & $9.3(4.4)$ \\
\hline CGI-S score (SD) & $4.6(0.7)$ & $2.3(0.8)$ \\
\hline
\end{tabular}

Abbreviations: BMI, body mass index; CGI-S, Clinical Global ImpressionsSeverity of Depression; MADRS, Montgomery-Åsberg Depression Rating Scale; $N$, number of patients involved in the summary; $n$, number of patients in the given category; OFC, olanzapine and fluoxetine hydrochloride combination; SD, standard deviation; SP, study period.

aDoes not include current episode. 
Table 2 Treatment-Emergent Adverse Events Reported in At Least 2\% of Patients (Study Periods II Through IV)

\begin{tabular}{|c|c|c|c|c|}
\hline Event, $n$ (\%) & SPII OFC $N=892$ & SPIII OFC N=655 & SPIV OFC $N=22 I$ & SPIV FLU $N=223$ \\
\hline Patients with $\geqslant 1$ TEAE & $610(68.4)$ & $352(53.7)$ & $105(47.5)$ & | || (49.8) \\
\hline Weight increased & $15 \mid(16.9)$ & $59(9.0)$ & $8(3.6)$ & $5(2.2)$ \\
\hline Dry mouth & $125(14.0)$ & $8(1.2)$ & $0(0.0)$ & I (0.4) \\
\hline Increased appetite & $123(13.8)$ & II (I.7) & $3(1.4)$ & I (0.4) \\
\hline Somnolence & $76(8.5)$ & $20(3.1)$ & । $(0.5)$ & $3(1.3)$ \\
\hline Sedation & $61(6.8)$ & $17(2.6)$ & $3(1.4)$ & $0(0.0)$ \\
\hline Nasopharyngitis & $37(4.1)$ & $23(3.5)$ & $9(4.1)$ & $12(5.4)$ \\
\hline Nausea & $34(3.8)$ & $18(2.7)$ & $10(4.5)$ & $8(3.6)$ \\
\hline Tremor & $33(3.7)$ & $10(1.5)$ & I (0.5) & $2(0.9)$ \\
\hline Restlessness & $22(2.5)$ & $7(1.1)$ & । $(0.5)$ & $0(0.0)$ \\
\hline Diarrhea & $20(2.2)$ & $5(0.8)$ & $5(2.3)$ & $6(2.7)$ \\
\hline Insomnia & $20(2.2)$ & $16(2.4)$ & $8(3.6)$ & $16(7.2)$ \\
\hline Upper respiratory tract infection & $9(1.0)$ & $20(3.1)$ & I| (5.0) & $7(3.1)$ \\
\hline Blood triglycerides increased & $17(1.9)$ & $15(2.3)$ & $4(1.8)$ & I $(0.4)$ \\
\hline Vomiting & $12(1.3)$ & $15(2.3)$ & $6(2.7)$ & $4(1.8)$ \\
\hline Depression & $3(0.3)$ & $5(0.8)$ & $5(2.3)$ & $15(6.7)$ \\
\hline Gastroenteritis & $4(0.4)$ & $6(0.9)$ & $6(2.7)$ & $3(1.3)$ \\
\hline
\end{tabular}

Abbreviations: FLU, fluoxetine; OFC, olanzapine and fluoxetine hydrochloride combination; SP, study period; TEAE, treatment-emergent adverse event.

met criteria for AIMS-defined treatment-emergent dyskinesia during SPIII. However, no patients reported any spontaneous AEs of dyskinesia during SPIII. During SPII, $10.0 \%$ of patients used benzodiazepines and $1.9 \%$ used anticholinergic drugs, whereas in SPIII, 9.1\% of patients used benzodiazepines and $1.4 \%$ used anticholinergic drugs.

During the open-label phases of the study, a significant mean increase from baseline to last visit was observed for weight ( $4.15 \mathrm{~kg} ; p<0.001)$. Mean changes from baseline to last visit in fasting metabolic parameters of glucose $(0.0 \mathrm{mmol} / \mathrm{l})$, cholesterol $(0.01 \mathrm{mmol} / \mathrm{l})$, low-density lipoprotein (LDL) cholesterol $(0.0 \mathrm{mmol} / \mathrm{l})$, high-density lipoprotein (HDL) cholesterol $(-0.05 \mathrm{mmol} / \mathrm{l})$, and triglycerides $(0.12 \mathrm{mmol} / \mathrm{l})$ were not statistically significant ( $p$-values $\geqslant 0.313$ ).

With regard to weight gain, $34.8 \%$ of patients' weight increased by $\geqslant 7 \%$ from their baseline, $6.2 \%$ increased by $\geqslant 15 \%$, and $1.1 \%$ increased by $\geqslant 25 \%$. Normal to high categorical changes were observed for fasting glucose in $6.6 \%$ of patients, cholesterol in 9.4\%, LDL cholesterol in $3.0 \%$, and triglycerides in $22.6 \%$, and $24.9 \%$ of patients had changes from normal to low HDL cholesterol.

\section{Relapse-Prevention Phase (SPIV)}

No treatment group differences were observed in any demographic or baseline clinical/psychiatric characteristics of randomized patients (Table 1B).
Of the $444(49.8 \%)$ patients that met stabilization criteria, 221 were randomized to OFC and 223 to fluoxetine. There were $37.1 \%$ of patients in the OFC group who discontinued compared with $47.5 \%$ in the fluoxetine group $(p=0.028)$. The most common reason for discontinuation was relapse criteria met (OFC, $N=24$ (10.9\%) vs fluoxetine, $N=63$ $(28.3 \%) ; p<0.001$; Figure 1b). Almost twice the number of OFC patients discontinued owing to AEs (OFC, $N=19$ $(8.6 \%) v s$ fluoxetine, $N=10(4.5 \%) ; p=0.061)$.

Efficacy. A Kaplan-Meier plot of time-to-relapse, using the primary definition of relapse, is presented in Figure 2. OFC-treated patients showed a significantly longer time-torelapse $(p<0.001)$ than did fluoxetine-treated patients. Time-to-relapse analyzed by each of the individual criteria was consistent with the primary definition, with the exception of hospitalizations, which were too few to generate a strong test. Relapse rates were lower for OFC $v s$ fluoxetine (primary definition: $15.8 \%$ vs $31.8 \%$ of patients; scale-based definition: $14.0 \%$ vs $28.3 \%$ of patients; and discontinuation-based definition: $10.9 \%$ vs $28.3 \%$ of patients; each test yielded $p<0.001)$. Following the observed results of the KaplanMeier analysis, a Cox proportional hazards analysis under the primary relapse definition generated a hazard ratio of 2.37 (fluoxetine:OFC) and 95\% confidence interval (1.58, 3.55), indicating that the hazard of relapse for the fluoxetine group was approximately twice that of the OFC group. 
Table I B Baseline Patient Demographics and Clinical Characteristics of Patients (Study Period IV)

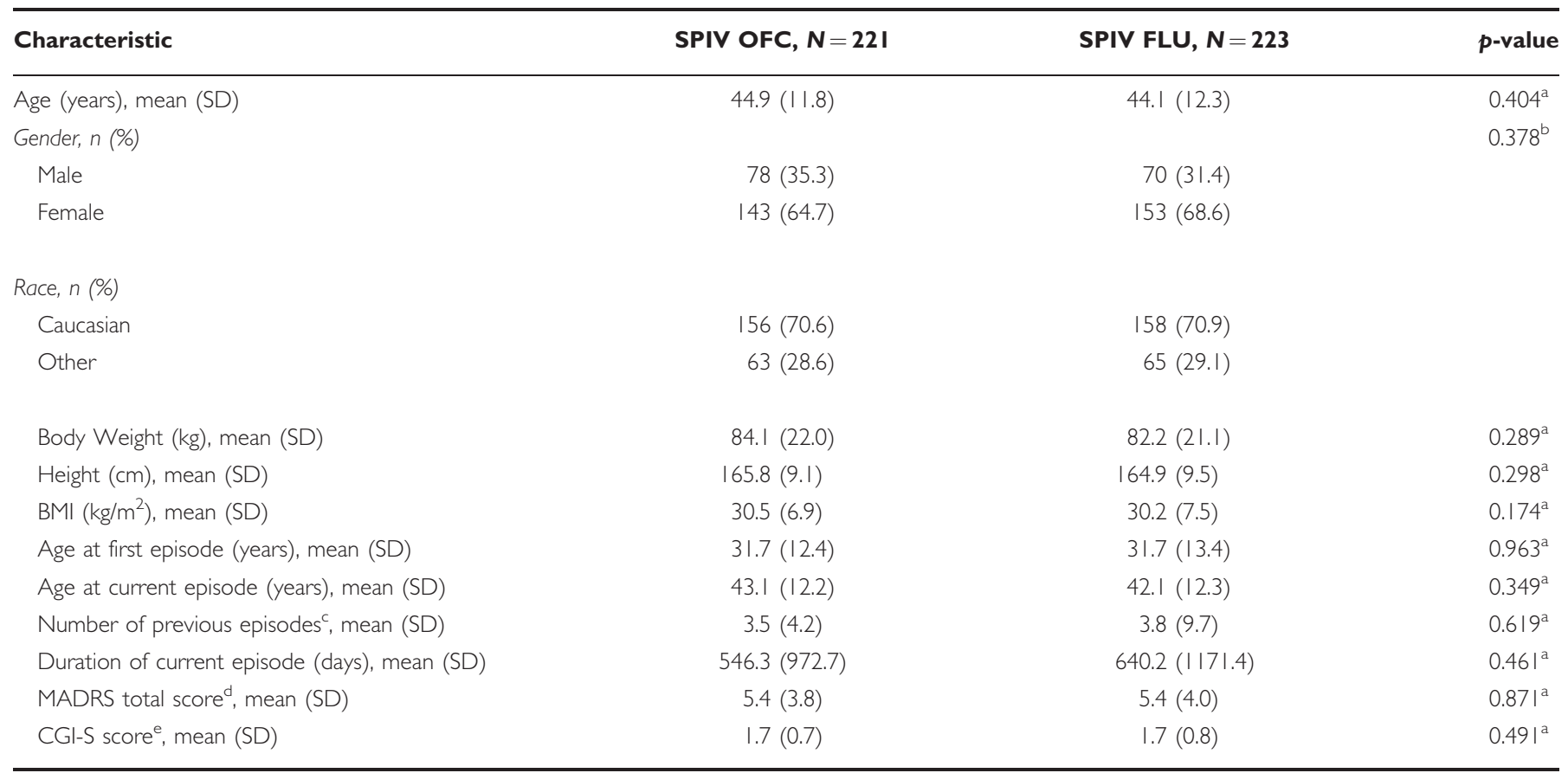

Abbreviations: ANOVA, analysis of variance; BMI, body mass index; CGI-S, Clinical Global Impressions-Severity of Depression; CMH, Cochran-Mantel-Haenszel; FLU, fluoxetine; LS, least squares; MADRS, Montgomery-Åsberg Depression Rating Scale; $N$, number of patients involved in the summary; $n$, number of patients in the given category; OFC, olanzapine and fluoxetine hydrochloride combination; SD, standard deviation; SE, standard error; SP, study period.

a $p$-values are from ANOVA with treatment and country as independent variables in the model.

${ }^{b} p$-values are from $\mathrm{CMH}$ test adjusting by country.

'Does not include current episode.

dMADRS mean change at endpoint (LS Mean (SE)): 3.0 (0.7), OFC; 6.8 (0.7), FLU; $p<0.001$.

${ }^{e} \mathrm{CGI}-\mathrm{S}$ mean change at endpoint (LS Mean (SE)): 0.2 (0.I), OFC; 0.5 (0.I), FLU; $p=0.002$.

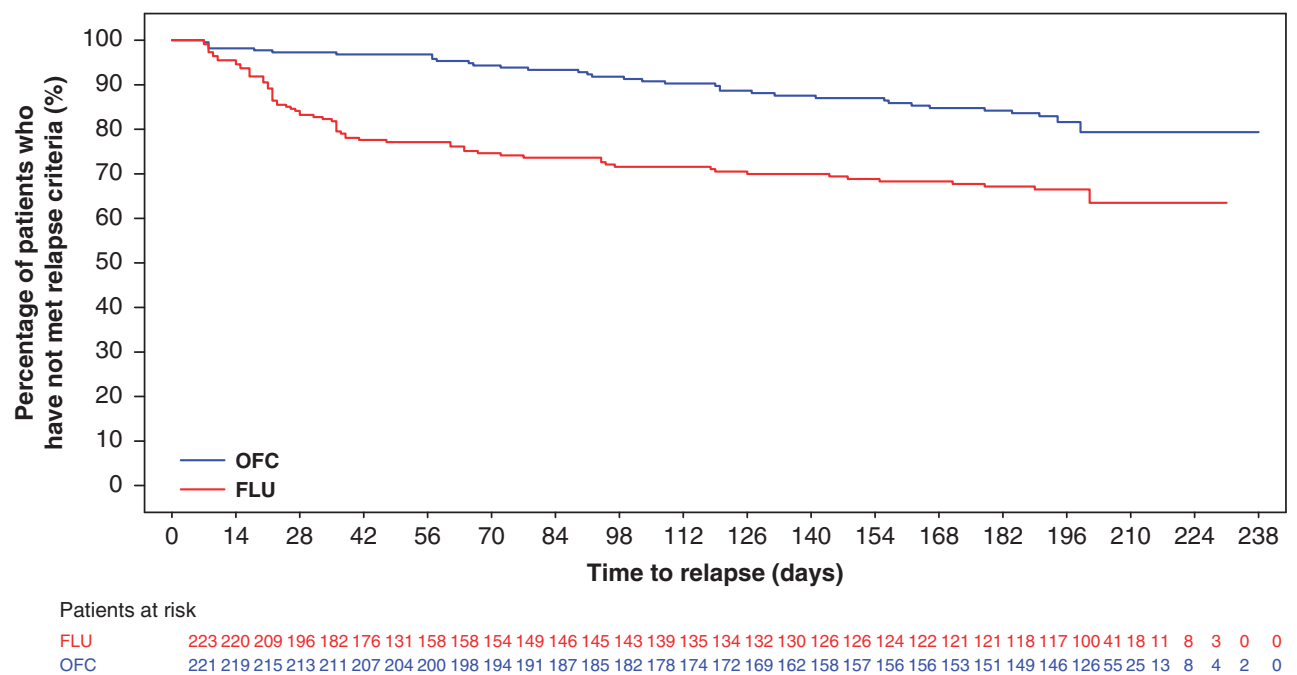

Figure 2 Time-to-relapse (primary definition). Patients who have not met relapse criteria are considered as censored at the time of discontinuation. Logrank test was used for treatment group comparison $(p<0.00 \mathrm{I})$. FLU, fluoxetine; OFC, olanzapine and fluoxetine hydrochloride combination.

During SPIV, there was no difference between groups in incidence of patients who met response at any time after randomization (OFC $n=215(97.3 \%)$, fluoxetine $n=210$ $(94.2 \%))(p=0.126)$. More OFC-treated patients $(n=191$
(86.4\%)) compared with fluoxetine-treated patients $(n=176$ $(78.9 \%)$ ) met the remission definition at any time $(p=0.047)$ and at endpoint $(n=136(61.5 \%)$ vs $n=112$ $(50.2 \%) ; p=0.011)$. 
For OFC-treated patients, mean total MADRS score increased from 5.36 at baseline to 8.07 at endpoint (least squares (LS) mean change, 3.0) compared with an increase from 5.40 at baseline to 11.82 at endpoint (LS mean change, 6.8) $(p<0.001)$ for fluoxetine-treated patients. Similar mean changes in favor of OFC were observed from baseline to endpoint CGI-S scores $(p=0.002)$.

The mean change in Sheehan Disability Scale global functional impairment total score from baseline was greater in fluoxetine-treated patients than in OFC-treated patients at endpoint (LS mean change: fluoxetine, 3.24; OFC, 1.30; $p=0.007$ ), indicating less worsening in functional impairment in OFC-treated patients during SPIV. A difference was also observed for the three subscores.

Results from the Resource Utilization Questionnaire evaluation revealed that the majority of patients taking fluoxetine and OFC were living either independently $(29.3 \%$ and $34.5 \%$, respectively) or with family members $(69.8 \%$ and $63.3 \%$, respectively) at endpoint. Patients taking fluoxetine and OFC, $52.6 \%$ and $49.6 \%$, respectively, were working for pay, with $2.6 \%$ unemployed owing to depression and $19.0 \%$ unemployed unrelated to depression for patients taking fluoxetine, and $7.2 \%$ unemployed owing to depression and $16.5 \%$ unemployed unrelated to depression for patients taking OFC.

Safety. There was one death during the study (in SPIV). A 50-year-old male, randomly assigned to ongoing OFC treatment, was admitted at the intensive care unit for hemoptysis and was diagnosed with widely spread metastatic cancer, primary believed to be lung, but unknown. The subject had a history of $30+$ years of smoking and chronic obstructive pulmonary disease, and death was judged by the investigator as unrelated to study medication.

No significant differences between treatment groups were observed in occurrence of SAEs $(p=0.621)$. Sixteen patients (OFC, $n=9(4.1 \%)$ vs fluoxetine, $n=7(3.1 \%)$ ) reported $\geqslant 1$ SAE during SPIV. The most frequently occurring SAE and the only event reported in $>1$ patient in both treatment groups was depression (OFC, three (1.4\%); fluoxetine, three $(1.3 \%))$. TEAEs were reported in $105(47.5 \%)$ OFC-treated patients and $111(49.8 \%)$ fluoxetine-treated patients, with no significant difference between treatment groups $(p=0.636$, Table 2$)$. Twice as many OFC-treated patients discontinued owing to an $\mathrm{AE}$ with weight increase being most common $(n=6(2.7 \%))$. The most frequent reasons for discontinuation owing to an $\mathrm{AE}$ in fluoxetine-treated patients were increased weight $(n=2(0.9 \%))$ and anxiety $(n=2(0.9 \%))$. There were no TEAEs occurring at a frequency $\geqslant 10 \%$. No OFC-treated patients and one fluoxetinetreated patient $(0.4 \%)$ reported treatment-emergent mania. No significant differences were observed between treatments in time to discontinuation owing to AEs $(p=0.236)$.

There were no significant differences in overall concomitant medication use between treatments; however, more fluoxetine-treated patients (31 (13.9\%)) concomitantly used $\geqslant 1$ benzodiazepine or anticholinergic medication compared with OFC-treated patients (15 (6.8\%); $p=0.008)$. A total of $6.3 \%$ of OFC-treated patients used benzodiazepines compared with $12.6 \%$ of fluoxetine-treated patients. Additionally, $0.5 \%$ of OFC-treated patients used anticholinergic drugs, whereas $1.8 \%$ of fluoxetine-treated patients used anticholinergic drugs during SPIV.

Two $(0.9 \%)$ OFC-treated patients and two $(0.9 \%)$ fluoxetine-treated patients experienced treatment-emergent akathisia $(p=1.000)$. Three $(1.4 \%)$ OFC-treated patients experienced treatment-emergent Parkinsonism compared with no fluoxetine-treated patients $(p=0.248)$. One OFCtreated patient $(0.5 \%)$ and no fluoxetine-treated patients reported dyskinesia $(p=1.000)$. During SPIV, $4.1 \%(n=9)$ of OFC-treated patients reported suicidal ideation based on C-SSRS compared with $6.3 \%(n=14)$ of fluoxetine-treated patients $(p=0.392)$. No patients exhibited suicidal behaviors. Suicide-related behavior and ideation assessed by C-SSRS demonstrated no differences between OFC and fluoxetine treatments $(p>0.274)$. There were no significant differences between treatment groups in the incidence of suicide-related behavior and ideation with no reports of suicidal acts.

Weight and metabolic categorical and mean changes from baseline are presented in Tables $3 \mathrm{~A}$ and $3 \mathrm{~B}$. There were significant differences in the percentage of patients who experienced clinically significant $(\geqslant 7 \%)$ weight loss (OFC: $5.0 \%$, fluoxetine: $15.3 \% ; p<0.001$ ) and weight gain (OFC: $11.8 \%$, fluoxetine: $2.3 \% ; p<0.001$ ). At endpoint, mean differences were significant for weight (OFC: $1.14 \mathrm{~kg}$, fluoxetine: $-2.78 \mathrm{~kg} ; p<0.001)$. In general, categorical and mean glucose, triglyceride, and cholesterol changes (decreases in HDL) were greater in OFC-treated patients. More OFC-treated patients experienced categorical high prolactin values compared with fluoxetine-treated patients $(14.9 \%$ vs $6.3 \%$ respectively, $p=0.009$ ).

At endpoint, differences were observed for standing diastolic blood pressure (OFC: $-0.21 \mathrm{~mm} \mathrm{Hg}$, fluoxetine: $-1.74 \mathrm{~mm} \mathrm{Hg} ; p=0.044$ ). There were no significant treatment group differences in mean changes from baseline in electrocardiographic intervals and heart rate. The only changes noted within treatment groups were for OFCtreated patients in QRS interval (LS mean change, $1.50 \mathrm{~ms}$; $p=0.022$ ), and QTcF interval (LS mean change, $-3.12 \mathrm{~ms}$; $p=0.036$ ), and QTcR interval regression correction (LS mean change, $-3.11 \mathrm{~ms} ; p=0.043)$. The risk of induction of mania was low for the full duration of the study in both treatment groups with only a single mania-related event reported for fluoxetine treatment.

\section{DISCUSSION}

Adjunctive therapy with SGAs has proven useful for patients who have had an inadequate response to antidepressant medications in patients with TRD (Connolly and Thase, 2012; Han et al, 2013). The combination of olanzapine and fluoxetine has similarly been shown to be an effective treatment for patients with TRD (Shelton et al, 2005; Thase et al, 2007). Nevertheless, the question remains regarding how long to continue the adjunctive SGA when the strategy has been effective. Although one might assume that both the SGA and the antidepressant may need to be continued, to date the only relevant study conducted in a TRD patients reported a lack of additional benefit beyond short-term treatment with risperidone augmentation of citalopram therapy (Rapaport et al, 2006).

Our study, thus, was designed to answer this important clinical question, and the primary objective of the study was 
Table 3A Weight and Metabolic Safety Treatment-Emergent Categorical Changes, Relapse-Prevention Phase

\begin{tabular}{|c|c|c|c|c|c|c|}
\hline Parameter $^{\mathbf{a}}$ & Abnormality direction & Criteria at baseline & Criteria at endpoint & OFC $n / N(\%)$ & FLU $n / N(\%)$ & $p$-value ${ }^{b}$ \\
\hline \multirow[t]{2}{*}{ Weight $^{c}$} & $N$ to $L$ & N/A & Decrease $\geqslant 7 \%$ & | I/220 (5.0) & $34 / 222(15.3)$ & $<0.001$ \\
\hline & $\mathrm{N}$ to $\mathrm{H}$ & $N / A$ & Increase $\geqslant 7 \%$ & $26 / 220(11.8)$ & $5 / 222(2.3)$ & $<0.00$ । \\
\hline \multirow[t]{3}{*}{ Glucose (mmol/l) } & I to $\mathrm{H}$ & $\geqslant 5.55$ and $<6.99$ & $\geqslant 6.99$ & | 8/98 (18.4) & $7 / 97(7.2)$ & 0.031 \\
\hline & $\mathrm{N}$ to $\mathrm{H}$ & $<5.55$ & $\geqslant 6.99$ & $4 / 90(4.4)$ & $5 / 96(5.2)$ & 1.000 \\
\hline & $\mathrm{N}$ to I & $<5.55$ & $\geqslant 5.55$ and $<6.99$ & $32 / 90(35.6)$ & $27 / 96(28.1)$ & 0.344 \\
\hline \multirow{2}{*}{ Cholesterol (mmol/l) } & $N$ to $B$ & $<6.22$ & $\geqslant 5.18$ and $<6.22$ & $8 / 47(17.0)$ & $10 / 59(16.9)$ & 1.000 \\
\hline & $\mathrm{N}$ to $\mathrm{H}$ & $<6.22$ & $\geqslant 6.22$ & I/47 (2.1) & 2/59 (3.4) & 1.000 \\
\hline \multirow[t]{3}{*}{ LDL Cholesterol (mmol/l) } & $\mathrm{B}$ to $\mathrm{H}$ & $\geqslant 2.59$ and $<4.14$ & $\geqslant 4.14$ & $20 / 115(17.4)$ & |4/I34 (I0.4) & 0.139 \\
\hline & $N$ to $B$ & $<2.59$ & $\geqslant 2.59$ and $<4.14$ & $5 / 22(22.7)$ & $8 / 26(30.8)$ & 0.746 \\
\hline & $\mathrm{N}$ to $\mathrm{H}$ & $<2.59$ & $\geqslant 4.14$ & $1 / 22(4.5)$ & $0 / 26(0.0)$ & 0.458 \\
\hline \multirow{2}{*}{ Triglycerides (mmol/l) } & $\mathrm{N}$ to $\mathrm{EH}$ & $<1.70$ & $\geqslant 5.65$ & $0 / 68(0.0)$ & $0 / 74(0.0)$ & N/A \\
\hline & $\mathrm{N}$ to $\mathrm{H}$ & $<1.70$ & $\geqslant 2.26$ & II/68 (16.2) & $4 / 74(5.4)$ & 0.054 \\
\hline
\end{tabular}

Abbreviations: B, borderline; EH, extremely high; FLU, fluoxetine; H, high; HDL, high-density lipoprotein; I, impaired; L, low; LDL-low-density lipoprotein; N, normal; $\mathrm{N}$, number of patients involved in the summary; $n$, number of patients in the given category; N/A, not applicable; OFC, olanzapine and fluoxetine hydrochloride combination.

${ }^{a}$ Changes in metabolic parameters were measured in a fasting state.

b p-values from Fisher's exact test.

${ }^{\mathrm{C}}$ Refers to change in weight for patients during the relapse-prevention phase who were normal at baseline.

Table 3B Mean Change from Baseline in Weight and Metabolic Safety Parameters, Relapse-Prevention Phase

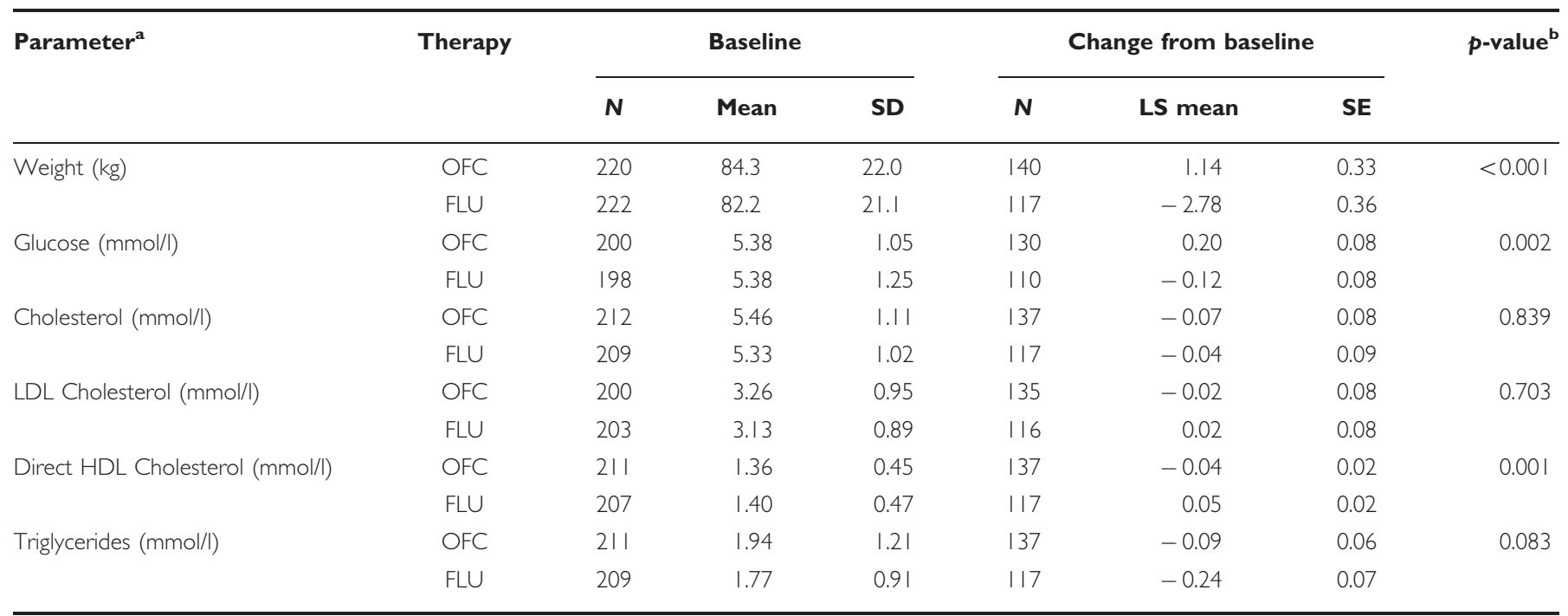

Abbreviations: FLU, fluoxetine; HDL, high-density lipoprotein; LDL, low-density lipoprotein; LS, least squares; N, number of patients involved in the summary; OFC, olanzapine and fluoxetine hydrochloride combination; SD, standard deviation; SE, standard error.

${ }^{a}$ Changes in metabolic parameters were measured in a fasting state.

${ }^{b} p$-values from $t$-test of between group LS Mean difference.

met as patients treated with OFC $v$ fluoxetine experienced longer times to relapse. Also, OFC-treated subjects demonstrated higher remission rates and lower relapse rates.
Response rates were not different between the two treatments; a likely result of various factors such as subjects having already received open-label acute and stabilization 
treatment benefits of OFC for $\leqslant 20$ weeks, the fact that response was required for patients entering SPIV (a threshold easily reached or maintained during this study phase), and finally, that fluoxetine is an established effective antidepressant. Although both groups experienced mean increases in MADRS during the double-blind period, changes were smaller for OFC than for fluoxetine. This may have clinical relevance as the mean MADRS at 27 weeks for OFC-treated patients was within the remission threshold of $\leqslant 8$ but above the remission threshold for the fluoxetine group (11.8), consistent with findings of greater likelihood of remission at endpoint with OFC treatment. The risks associated with a lack of remission during treatment or a higher likelihood of relapse with treatment include suicide, increased treatment costs, poorer outcomes, and greater morbidity (McIntyre and O'Donovan, 2004). Although, in this study, we found no differences in frequency of suicidal ideation and behaviors rated by the C-SSRS and, at best, inconsistent functional benefits between the two treatments; however, the Sheehan disability scale suggests lesser worsening in functional impairment with OFC. Previous studies of OFC in TRD have been of short-term duration (Corya et al, 2006; Shelton et al, 2001, 2005; Thase et al, 2007; Trivedi et al, 2009); however, the present results provide data that support the potential use of OFC in longterm TRD treatment.

This study has several pragmatic aspects of clinical relevance. First, it mimics real-life clinical practice, such as when an antipsychotic combined with an antidepressant for TRD treatment is being considered for discontinuation. When this occurs, it is likely that the same antidepressant will be continued; hence, the study provides clinically relevant information regarding long-term treatment choices for patients with TRD acutely treated and stabilized with OFC. Second, it begins to address a common and important clinical conundrum related to the adjunctive use of antipsychotics in a (resistant) depressed population, and the well-known short- and long-term risks of SGAs (especially weight and metabolic changes). So, despite the clinically relevant and important efficacy and potential functional findings in this study of continued OFC treatment compared with fluoxetine as reported above, the clinician must weigh these benefits against the possible added risks of keeping the patient on a SGA, particularly the risks of weight gain and other metabolic changes. This study may not answer all of these questions, but the incidence of SAEs and TEAEs in this study were not different between treatments during the relapse-prevention phase. This may well be due to a certain degree of tolerance already developed with $\leqslant 20$ weeks of open-label OFC treatment. This tolerance or prior exposure may also explain the absence of EPS (Parkinson's, Akathisia, or Tardive Dyskinesia) and prolactin differences between the two treatments. However, twice as many patients randomized to OFC discontinued owing to an $\mathrm{AE}$, weight gain being the most common reason, and patients generally had greater significant mean increases and greater categorical changes in weight, glucose, triglycerides, and HDL cholesterol. These metabolic findings are consistent with previous analyses of long-term weight and metabolic changes in adults treated with olanzapine or OFC (Kryzhanovskaya et al, 2012; Symbyax ${ }^{\mathrm{TM}}$ prescribing information, 2013; Zyprexa prescribing information, 2013).
To provide additional perspective about the potential for longer-term weight changes with OFC, Andersen et al (2005) published a 76-week open-label analysis on weight gain in subjects with MDD (26\% with TRD) and reported a similar percentage of subjects who gained $\geqslant 7 \%$ of their baseline weight (56\%); a Kaplan-Meier curve of time to $\geqslant 7 \%$ gain seems to plateau after 40 weeks of treatment; and the median time to $\geqslant 7 \%$ weight gain was 16 weeks, which could partially explain the apparent lack of difference in clinically significant weight gain after 47 and 76 weeks of treatment.

Some limitations to this study should be considered. The study may have had better signal detection if it had used at least one prospective treatment trial to establish the required history of TRD. However, this design feature would have increased the duration of the study and increased discontinuation rates. We note that the retrospective approach used in the study is consistent with the definition (and identification) of patients with TRD for which OFC is indicated as short-term therapy (Symbyax prescribing information, 2013). Further, the study design incorporated a blinded olanzapine taper to prevent the possibility of unblinding due to rapid discontinuation of olanzapine during SPIV. Another limitation is that fluoxetine was the only antidepressant used as a comparator. We recognize that the use of olanzapine in combination with other currently available antidepressants, some with a different mechanism of action, would have broadened the generalizability of the findings. Last, as a relapse-prevention study may be viewed as an example of an enriched design (ie, all randomized patients had both tolerated and responded to therapy with $\mathrm{OFC}$ ), our results may not be generalizable to patients who do not respond to OFC or who have not had prior exposure to OFC.

Continued maintenance with OFC treatment rather than switching to fluoxetine therapy after stabilization on OFC was significantly superior in time-to-relapse and risk-ofrelapse in the long-term treatment of TRD. The safety findings during long-term OFC treatment in this study were consistent with OFC's known safety profile (Corya et al, 2003; Thase et al, 2007; Trivedi et al, 2009; Symbyax prescribing information, 2013). The decision to continue treatment with OFC or fluoxetine must be based on individual patient needs and balanced against the potential for metabolic changes that may occur with long-term OFC treatment. Although continued treatment with fluoxetine alone may still be a valid treatment option for some patients, shorter time-to-relapse, significantly higher relapse rates, and lower remission rates observed with fluoxetine in this study must also be considered.

\section{FUNDING AND DISCLOSURE}

Funding for this study was provided by Eli Lilly and Company, which also designed the study, performed the collection, analysis, and interpretation of the data, the writing of this report, and made the decision to submit the paper for publication. Dr Brunner, Dr Osuntokun, and $\mathrm{Mr}$ Landry are full-time employees of, and minor stockholders in, Eli Lilly and Company. Dr Thase has acted as advisor/ consultant for a number of pharmaceutical companies, including Eli Lilly and Company. He has received grant 
support from the Agency for Healthcare Research and Quality, Alkermes, AstraZeneca, Eli Lilly and Company, Forest Pharmaceuticals, Johnson \& Johnson, Naurex Pharmaceuticals, National Institute of Mental Health, Otsuka Pharmaceuticals, and Roche Laboratories. Dr Tohen was formerly employed by Eli Lilly and Company (to 2008) and has received honoraria or consulted for AstraZeneca, BristolMyersSquibb, Glaxo-SmithKline, Forest, Eli Lilly, Johnson \& Johnson, Merck, Otsuka, Sepracor, Sunovion, Lundbeck and Wyeth Corporations.

\section{ACKNOWLEDGEMENTS}

The authors would like to thank Shannon Gardell, PhD (inVentiv Health Clinical, LLC) for assistance with preparation of the manuscript.

\section{REFERENCES}

American Psychiatric Association (2000). Diagnostic and Statistical Manual of Mental Disorders, Fourth Edition, Text Revision. American Psychiatric Association: Washington, DC, USA.

American Psychiatric Association (2010). Practice Guideline for the Treatment of Patients with Major Depressive Disorder. Third Edition American Psychiatric Association: Washington, DC, USA.

Andersen SW, Clemow DB, Corya SA (2005). Long-term weight gain in patients treated with open-label olanzapine in combination with fluoxetine for major depressive disorder. J Clin Psychiatry 66: 1468-1476.

Anderson IM, Ferrier IN, Baldwin RC, Cowen PJ, Howard L, Lewis $\mathrm{G}$ et al (2008). Evidence-based guidelines for treating depressive disorders with antidepressants: a revision of the 2000 British Association for Psychopharmacology guidelines. J Psychopharmacol 22: 343-396.

Baldomero EB, Ubago JG, Cercos CL, Ruiloba JV, Calvo CG, Lopez RP (2005). Venlafaxine extended release versus conventional antidepressants in the remission of depressive disorders after previous antidepressant failure: ARGOS study. Depress Anxiety 22: $68-76$.

Barnes TRE (1989). A rating scale for drug-induced akathisia. $\mathrm{Br} J$ Psychiatry 154: 672-676.

Bauer M, Whybrow PC, Angst J, Versiani M, Möller HJ (2002). World Federation of Societies Biological Psychiatry Task Force on Treatment Guidelines for Unipolar Depressive Disorders. World Federation of Societies of Biological Psychiatry (WFSBP) guidelines for biological treatment of unipolar depressive disorders, Part 1: acute and continuation treatment of major depressive disorder. World J Biol Psychiatry 3: 5-43.

Berwaerts J, Lane R, Nuamah IF, Lim P, Remmerie B, Hough DW (2011). Paliperidone extended-release as adjunctive therapy to lithium or valproate in the treatment of acute mania: a randomized, placebo-controlled study. J Affect Disord 129: 252-260.

Blier P, Gobbi G, Turcotte JE, de Montigny C, Boucher N, Hebert C et al (2009). Mirtazapine and paroxetine in major depression: a comparison of monotherapy versus their combination from treatment initiation. Eur Neuropsychopharmacol 19: 457-465.

Blier P, Ward HE, Tremblay P, Laberge L, Hebert C, Bergeron R (2010). Combination of antidepressant medications from treatment initiation for major depressive disorder: a double-blind randomized study. Am J Psychiatry 167: 281-288.

Carpenter LL, Yasmin S, Price LH (2002). A double-blind, placebocontrolled study of antidepressant augmentation with mirtazapine. Biol Psychiatry 51: 183-188.
Connolly KR, Thase ME (2012). Emerging drugs for major depressive disorder. Expert Opin Emerg Drugs 17: 105-126.

Corya SA, Andersen SW, Detke HC, Kelly LS, Van Campen LE, Sanger TM et al (2003). Long-term antidepressant efficacy and safety of olanzapine/fluoxetine combination: a 76-week openlabel study. J Clin Psychiatry 64: 1349-1356.

Corya SA, Williamson D, Sanger TM, Briggs SD, Case M, Tollefson $\mathrm{G}$ (2006). A randomized, double-blind comparison of olanzapine/fluoxetine combination, olanzapine, fluoxetine, and venlafaxine in treatment-resistant depression. Depress Anxiety 23: 364-372.

Crown WH, Finkelstein S, Berndt ER, Ling D, Poret AW, Rush AJ et al (2002). The impact of treatment-resistant depression on health care utilization and costs. J Clin Psychiatry 63: 963-971.

De Bartolomeis A, Perugi G (2012). Combination of aripiprazole with mood stabilizers for the treatment of bipolar disorder: from acute mania to long-term maintenance. Expert Opin Pharmacother 13: 2027-2036.

Gaynes BN, Rush AJ, Trivedi MH, Wisniewski SR, Spencer D, Fava $M$ (2008). The $S T A{ }^{\star} D$ study: treating depression in the real world. Cleve Clin J Med 75: 57-66.

Greden JF (2001). The burden of disease for treatment-resistant depression. J Clin Psychiatry 62: 26-31.

Han C, Wang SM, Kato M, Lee SJ, Patkar AA, Masand PS et al (2013). Second-generation antipsychotics in the treatment of major depressive disorder: current evidence. Expert Rev Neurother 13: 851-870.

Ishak WW, Greenberg JM, Cohen RM (2013). Predicting relapse in major depressive disorder using patient-reported outcomes of depressive symptom severity, functioning, and quality of life in the individual burden of illness index for depression (IBI-D). J Affect Disord 151: 59-65.

Kemp DE, Karayal ON, Calabrese JR, Sachs GS, Pappadopulos E, Ice KS et al (2012). Ziprasidone with adjunctive mood stabilizer in the maintenance treatment of bipolar I disorder: long-term changes in weight and metabolic profiles. Eur Neuropsychopharmacol 22: 123-131.

Kennedy SH, Lam RW, Parikh SV, Patten SB, Ravindran AV (2009). CANMAT Depression Work Group. Canadian Network for Mood and Anxiety Treatments (CANMAT) Clinical guidelines for the management of major depressive disorder in adults. J Affect Disord 117: S1-S2.

Kryzhanovskaya LA, Xu W, Millen BA, Acharya N, Jen KY, Osuntokun O (2012). Comparison of long-term (at least 24 weeks) weight gain and metabolic changes between adolescents and adults treated with olanzapine. J Child Adolesc Psychopharmacol 22: 157-165.

Maes M, Libbrecht I, van Hunsel F, Campens D, Meltzer HY (1999). Pindolol and mianserin augment the antidepressant activity of fluoxetine in hospitalized major depressed patients, including those with treatment resistance. J Clin Psychopharmacol 19: 177-182.

McIntyre RS, O'Donovan C (2004). The human cost of not achieving full remission in depression. Can J Psychiatry 49: 10S-16S.

Montgomery SA, Asberg M (1979). A new depression scale designed to be sensitive to change. Br J Psychiatry 134: 382-389.

Nelson JC, Mazure CM, Jatlow PI, Bowers MB Jr, Price LH (2004). Combining norepinephrine and serotonin reuptake inhibition mechanisms for treatment of depression: a double-blind, randomized study. Biol Psychiatry 55: 296-300.

Papakostas GI, Petersen T, Pava J, Masson E, Worthington JJ 3rd, Alpert JE et al (2003). Hopelessness and suicidal ideation in outpatients with treatment-resistant depression: prevalence and impact on treatment outcome. J Nerv Ment Dis 191: 444-449.

Posner K, Brown GK, Stanley B, Brent DA, Yershova KV, Oquendo MA et al (2011). The Columbia- Suicide Severity Rating Scale (C-SSRS): Initial Validity and Internal Consistency Findings 
from Three Multi-Site Studies with Adolescents and Adults. Am J Psychiatry 168: 1266-1277.

Psychopharmacology Research Branch, National Institute of Mental Health (1976a). Abnormal lnvoluntary Movement Scale (AIMS). In: Guy W (eds). ECDEU Manual for Psychopharmacology, Revised. US Dept Health, Education, and Welfare publication (ADM) 76-338. National Institute of Mental Health: Rockville, Md, USA, 534-537.

Psychopharmacology Research Branch, National Institute of Mental Health (1976b). Clinical Global Impressions (CGI). In: Guy W (eds). ECDEU Assessment Manual for Psychopharmacology, Revised. US Dept Health, Education, and Welfare publication (ADM) 76-338. National Institute of Mental Health: Rockville, Md, USA, 217-222.

Rapaport MH, Gharabawi GM, Canuso CM, Mahmoud RA, Keller $\mathrm{MB}$, Bossie CA et al (2006). Effects of risperidone augmentation in patients with treatment-resistant depression: results of openlabel treatment followed by double-blind continuation. Neuropsychopharmacology 31: 2505-2513.

Rush AJ, Trivedi MH, Wisniewski SR, Nierenberg AA, Stewart JW, Warden D et al (2006). Acute and longer-term outcomes in depressed outpatients requiring one or several treatment steps: a STAR $^{\star}$ D report. Am J Psychiatry 163: 1905-1917.

Sheehan DV, Harnett-Sheehan K, Raj BA (1996). The measurement of disability. Int Clin Psychopharmacol 11: 89-95.

Shelton RC, Tollefson GD, Tohen M, Stahl S, Gannon KS, Jacobs TG et al (2001). A novel augmentation strategy for treating resistant major depression. Am J Psychiatry 158: 131-134.

Shelton RC, Williamson DJ, Corya SA, Sanger TM, Van Campen LE, Case $\mathrm{M}$ et al (2005). Olanzapine/fluoxetine combination for treatment-resistant depression: a controlled study of SSRI and nortriptyline resistance. J Clin Psychiatry 66: 1289-1297.

Simpson GM, Angus JWS (1970). A rating scale for extrapyramidal side effects. Acta Psychiatr Scand Suppl 45: 11-19.

Symbyax prescribing information (2013; http://pi.lilly.com/us/ symbyax-pi.pdf.
Thase ME, Corya SA, Osuntokun O, Case M, Henley DB, Sanger TM et al (2007). A randomized, double-blind comparison of olanzapine/fluoxetine combination, olanzapine, and fluoxetine in treatment-resistant major depressive disorder. J Clin Psychiatry 68: 224-236.

Trivedi MH (2004). The link between depression and physical symptoms. Prim Care Companion J Clin Psychiatry 6: 12-16.

Trivedi MH, Rush AJ, Wisniewski SR, Nierenberg AA, Warden D, Ritz L et al (2006). Evaluation of outcomes with citalopram for depression using measurement-based care in $\mathrm{STAR}^{\star} \mathrm{D}$ : implications for clinical practice. Am J Psychiatry 163: 28-40.

Trivedi MH, Thase ME, Osuntokun O, Henley DB, Case M, Watson SB et al (2009). An integrated analysis of olanzapine/fluoxetine combination in clinical trials of treatment-resistant depression. J Clin Psychiatry 70: 387-396.

US Department of Health and Human Services, Public Health Services, Agency for Healthcare Research and Quality (1993). Clinical Practice Guideline 5: Depression in Primary Care, Vol 2. Treatment of Major Depression Publication No. 93-0551US Department of Health and Human Services: Rockville, MD, USA.

Wade AG, Häring J (2010). A review of the costs associated with depression and treatment noncompliance: the potential benefits of online support. Int Clin Psychopharmacol 25: 288-296.

Weisler RH, Nolen WA, Neijber A, Hellqvist A, Paulsson B (2011). Continuation of quetiapine versus switching to placebo or lithium for maintenance treatment of bipolar I disorder (Trial 144: a randomized controlled study). J Clin Psychiatry 72: $1452-1464$.

Zyprexa prescribing information (2013; http://pi.lilly.com/us/ zyprexa-pi.pdf.

cc) (i) (-) $\odot$ This work is licensed under a Creative Commons Attribution-NonCommercial-NoDerivs $3.0 \mathrm{Un}$ ported License. To view a copy of this license, visit http:// creativecommons.org/licenses/by-nc-nd/3.0/ 